\title{
Prevalence and pattern of infectious dermatoses referrals to clinical microbiologists in a tertiary hospital in Southern Nigeria
}

\author{
1, ${ }^{2}$ Osaigbovo, I. I. \\ ${ }^{1}$ Department of Medical Microbiology, School of Medicine, University of Benin, Benin City, Nigeria \\ ${ }^{2}$ Department of Medical Microbiology, University of Benin Teaching Hospital, Benin City, Nigeria \\ Correspondence to: iyabo.osaigbovo@uniben.edu
}

\begin{abstract}
:
Background: Infectious dermatoses are rife in low resource tropical countries. The consultative roles of clinical microbiologists in these countries are not portrayed in the literature. Specifically, their role in the management of infectious dermatoses has not been emphasized. The objective of this study is to determine the prevalence and pattern of infectious dermatoses referrals to an out-patient infectious disease clinic run by clinical microbiologists.

Method: A retrospective analysis of all outpatient referrals to the clinical microbiologists in a tertiary hospital in southern Nigeria from October 2016 to September 2018 was conducted. The infectious dermatoses referrals were further analysed for patient demographics and frequency of clinical diagnosis.

Results: A total of 545 consults were received, $82(15.0 \%)$ of which were outpatient referrals. Infectious dermatoses accounted for $67(81.7 \%)$ of the outpatient referrals. The male to female ratio was $0.9: 1$ and mean age was $39.7 \pm 17.9$ years. Paediatric referrals accounted for $10.4 \%$. The commonest referral diagnoses were tinea corporis/capitis in $28(41.8 \%)$, onchodermatitis in 15 $(22.4 \%)$ and onychomycosis in $10(14.9 \%)$. Leprosy was suspected in 5 cases $(7.5 \%)$, lymphatic filariasis in 5 cases $(7.5 \%)$, and pityriasis in 2 cases $(3.0 \%)$. Referral diagnosis in 27 cases $(38.8 \%)$ was a skin-related neglected tropical disease. Microbiological testing confirmed clinical suspicion in $31.3 \%$ of cases.

Conclusion: Infectious dermatoses referrals constitute a substantial proportion of referrals to clinical microbiologists in the study location. Clinical microbiologists must be adept in the diagnosis of mycotic and parasitic dermatoses. The trending global health interest in integrated management of skin NTDs should be exploited to advocate for more sensitive diagnostic testing for infectious dermatoses.
\end{abstract}

Keywords: Clinical, Microbiology, Infectious dermatoses, Consultation, Nigeria

Received February 23, 2019; Revised March 9, 2019; Accepted March 10, 2019

Copyright 2019 AJCEM Open Access. This article is licensed and distributed under the terms of the Creative Commons Attrition 4.0 International License (http://creativecommmons.org/licenses/by/4.0), which permits unrestricted use, distribution and reproduction in any medium, provided credit is given to the original author(s) and the source.

\section{Prévalence et caractéristiques des dermatoses infectieuses adressées à des microbiologistes cliniques dans un hôpital tertiaire du sud du Nigéria}

\author{
${ }^{1,2}$ Osaigbovo, I. I.
}




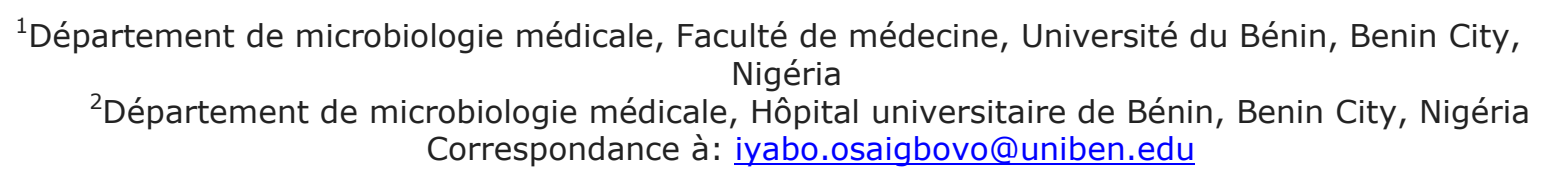

\section{Abstrait:}

Contexte: Les dermatoses infectieuses sévissent dans les pays tropicaux aux ressources limitées. Les rôles consultatifs des microbiologistes cliniques dans ces pays ne sont pas décrits dans la littérature. Plus précisément, leur rôle dans la gestion des dermatoses infectieuses n'a pas été souligné. L'objectif de cette étude est de déterminer la prévalence et les caractéristiques des dermatoses infectieuses dirigées vers une clinique de traitement des maladies infectieuses ambulatoire gérée par des microbiologistes cliniques

Méthode: Une analyse rétrospective de toutes les consultations externes vers les microbiologistes cliniques dans un hôpital tertiaire dans le sud du Nigéria d'octobre 2016 à septembre 2018 a été réalisée. Les références de dermatoses infectieuses ont ensuite été analysées pour déterminer les données démographiques des patients et la fréquence des

Résultats: Un total de 545 consultations ont été reçues, dont $82(15,0 \%)$ étaient des consultations externes. Les dermatoses infectieuses représentaient $67(81,7 \%)$ des consultations externes. Le ratio hommes/femmes était de 0,9: 1 et l'âge moyen était de 39,7 $\pm 17,9$ ans. Les références pédiatriques représentaient $10,4 \%$. Les diagnostics de référence les plus fréquents étaient les suivants: tinea corporis/capitis dans $28(41,8 \%)$, onchodermite dans $15(22,4 \%)$ et onychomycose dans $10(14,9 \%)$. La lèpre était suspectée dans 5 cas $(7,5 \%)$, la filariose lymphatique dans 5 cas $(7,5 \%)$ et le pityriasis dans 2 cas $(3,0 \%)$. Le diagnostic de référence dans 27 cas $(38,8 \%)$ était une maladie tropicale négligée liée à la peau. Les tests microbiologiques ont confirmé la suspicion clinique dans $31,3 \%$ des cas

Conclusion: Les références de dermatoses infectieuses constituent une proportion substantielle des références aux microbiologistes cliniques sur le lieu de l'étude. Les microbiologistes cliniques doivent être compétents dans le diagnostic des dermatoses mycotiques et parasitaires. L'intérêt actuel pour la santé mondiale dans la gestion intégrée des maladies tropicales négligées de la peau devrait être exploité pour plaider en faveur de tests de diagnostic plus sensibles des dermatoses infectieuses.

Mots-clés: Clinique, Microbiologie, Dermatoses infectieuses, Consultation, Nigéria

\section{Introduction:}

Promoted by poverty and the typically tropical climate, infectious dermatoses are rife in resource limited settings (1-3). A number of these dermatoses are cutaneous manifestations of neglected tropical diseases (NTDs), communicable diseases which occur among one billion of the most impoverished populations in the developing world (4). For many infectious dermatoses, particularly the skin-related NTDs, clinical signs are of variable specificity for making diagnoses: the manifestations of leprosy overlap with other skin diseases; chronic skin ulcers may be Buruli ulcer, cutaneous leishmaniasis or yaws; the lower limb swelling typical of lymphatic filariasis may also arise in podoconiosis, tuberculous lymphadenitis or even systemic diseases like heart failure (4). In some cases such as the dermatophytoses, clinical diagnosis is straightforward but laboratory identification is necessary to direct treatment and institute prophylactic measures (5). These reasons place a premium on the clinical microbiology laboratory in the management of infectious dermatoses

Clinical microbiologists possess an in-depth knowledge of infectious disease aetiology which positions them to provide clinical services extending beyond the laboratory bench (6). The extent to which they become involved in direct patient management is often dictated by other specialists who demand their services. Thus, their contributions are often not as visible as surgical or medical specialties (7). In western societies, such clinical roles have been highlighted in scholarly 
reviews and audits for the enlightenment of the medical community (6-9). The literature from sub-Saharan Africa is, however, devoid of studies reporting the consultative activities of clinical microbiologists.

At the University of Benin Teaching Hospital in Southern Nigeria, there has been a perceived demand for the skills of clinical microbiologists in sampling and diagnosis of infectious dermatoses. The aim of this study is to document the prevalence and pattern of infectious dermatoses referrals to clinical microbiologists at a tertiary hospital in Nigeria.

\section{Materials and methods:}

\section{Study setting}

This study was conducted at the University of Benin Teaching Hospital in Edo state, southern Nigeria. The hospital, which serves as a referral centre for surrounding states such as Ondo and Delta, is a 700 bed tertiary facility with a busy outpatients' department. The Medical Microbiology department houses the microbiology laboratory and offers clinical microbiology services provided by consultant clinical microbiologists sub serving administrative, consultative, teaching and research functions. Consultative functions include running of outpatient infectious disease diagnostic clinics.

\section{Study design}

This was a two-year retrospective review of referrals sent to the clinical microbiologists from October 2016 to September 2018. All out-patient infectious dermatoses referrals were retrieved and analysed for patient demographics. The distribution of dermatoses based on clinical suspicion was determined. Consultations involved brief historytaking; specimen collection; specimen processing and; microbiological testing including microscopy and culture. Sampling techniques employed were skin scraping for tinea and scabies, nail scraping for onychomycosis, skin snips for onchocerciasis, slit skin smears for leprosy and collection of night blood specimen for lymphatic filariasis.

\section{Data analysis}

Data were collated using Microsoft Excel and analysed. Descriptive statistics were calculated for key demographics and referral diagnoses. Frequencies were presented using tables and chart

\section{Ethical statement}

As this study involved a retrospective analysis of records, ethical review and approval was not required.

\section{Results:}

A total of 545 consults were received during the two-year review period; 463 ward-based consults and 82 referrals to the infectious disease clinic. Infectious dermatoses accounted for 67 $(81.7 \%)$ of the outpatient referrals. The dermatology clinic was the source of referral in 60 cases $(n=67,89.6 \%)$ while the general practice clinic accounted for the other referrals. Other outpatient referrals were ten $(12.1 \%)$ sexually transmitted infections (STIs), three $(3.7 \%)$ chronic respiratory tract infections and two $(2.4 \%)$ chronic urinary tract infections.

\section{Patient profile}

Sixty-seven patients with infectious dermatoses were seen: 32 males $(47.8 \%)$ and 35 females (52.2\%). The male to female ratio was 0.9:1. Mean age was $39.7 \pm 17.9$ years with a range of five to 83 years. Seven patients $(10.4 \%)$ were below 18 years of age.

\section{Referral diagnosis}

Fig 1 shows the relative distribution of infectious dermatoses suspected in the referrals received. As a single entity, the classical NTDs (onchodermatitis, lymphatic filariasis, leprosy and scabies) accounted for 27 $(38.8 \%)$ referrals. The commonest referral diagnosis in patients under 18 


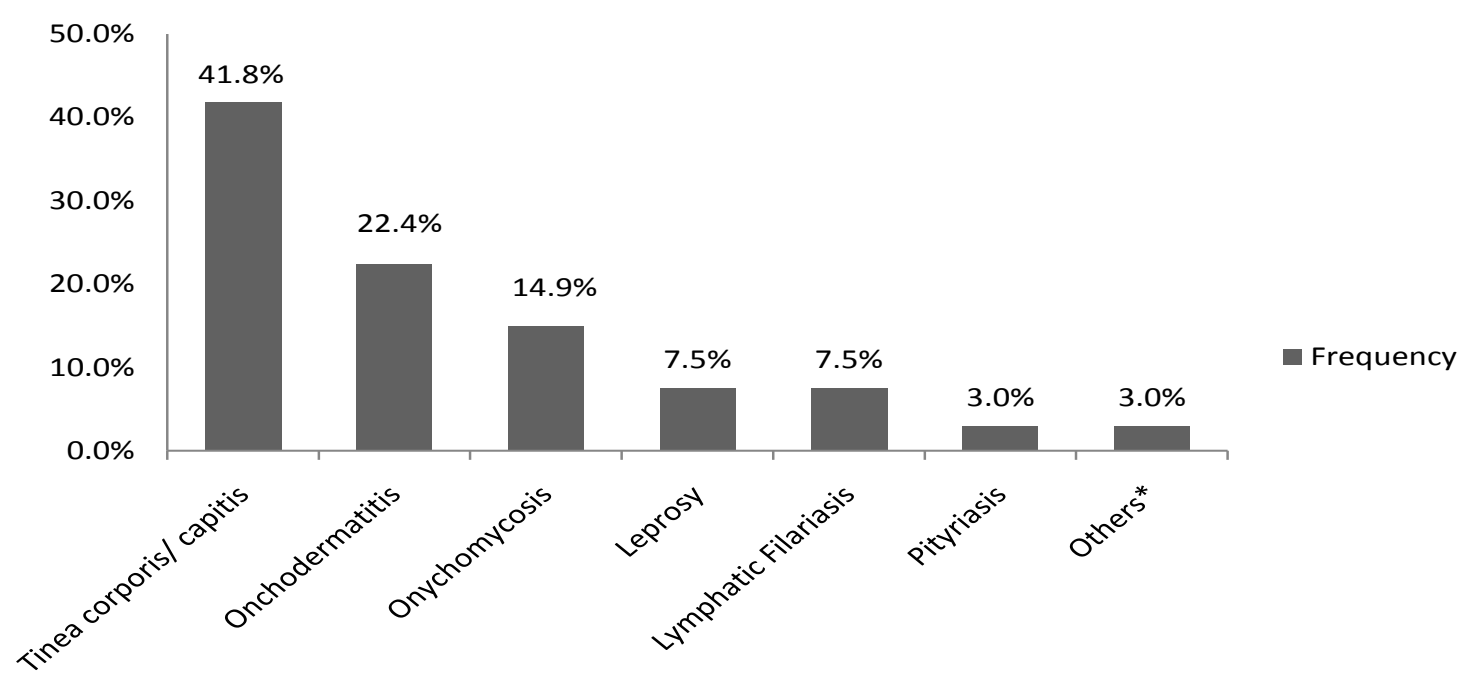

Fig 1: Frequency of infectious dermatoses according to clinical suspicion *Others = Scabies, Mycobacterial cutaneous ulcer

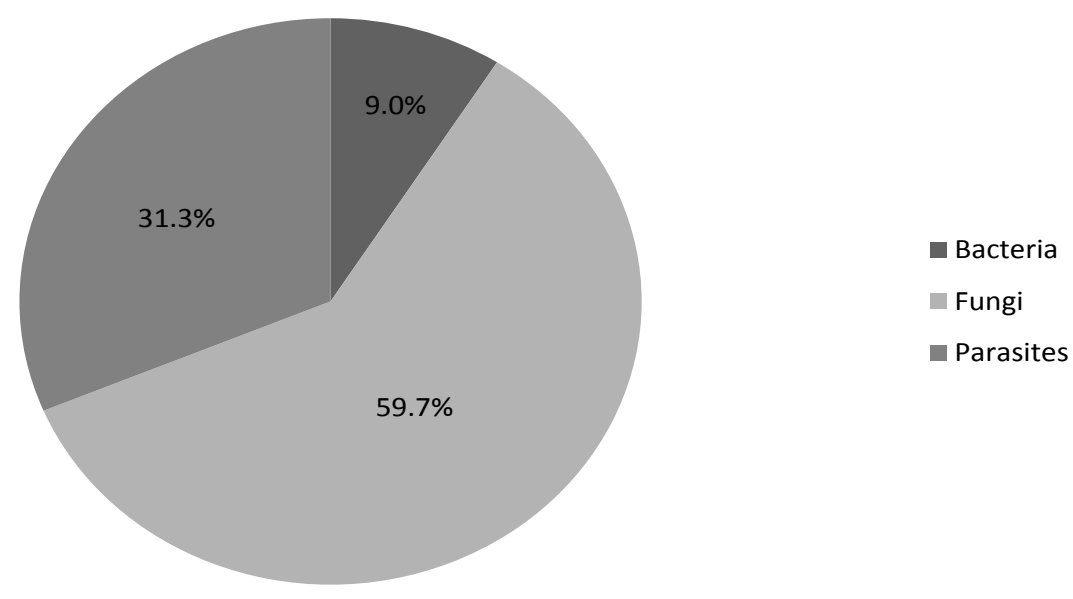

Figure 2: Frequency of infectious dermatoses referral diagnosis according to causative agents

years was tinea in six $(n=7,85.7 \%)$. Distribution of referral diagnosis based on causative agent is depicted in Figure 2.

\section{Microbiological analysis}

Microbiological testing which involved microscopy in all cases and culture for suspected fungal infections yielded a diagnosis in $31.3 \%$ of cases. Table 1 shows the categories of suspected dermatoses and the number with microbiological confirmation. Among confirmed cases of onychomycosis, there was one tinea unguim (microscopic evidence of dermatophyte infection only), one Candida onychomycosis caused by Candida krusei and two non dermatophyte mould (NDM) onychomycosis caused by Aspergillus niger. 
Table 1: Frequency of microbiological confirmation in suspected infectious dermatoses

\begin{tabular}{ccc}
\hline Dermatosis & Number of consultations & $\begin{array}{c}\text { Number with microbiological } \\
\text { confirmation (\%) }\end{array}$ \\
\hline Tinea capitis/ corporis & 28 & $7(25.0)$ \\
Onychomycosis & 10 & $4(40.0)$ \\
Onchodermatitis & 15 & $3(20.0)$ \\
Lymphatic filariasis & 5 & $0(0.0)$ \\
Leprosy & 5 & $4(80.0)$ \\
Pityriasis & 2 & $2(100.0)$ \\
Scabies & 1 & $1(100.0)$ \\
Mycobacterial skin ulcer & 1 & $0(0.0)$ \\
\hline Total & 67 & $21(31.3)$ \\
\hline
\end{tabular}

\section{Discussion:}

A key responsibility of clinical microbiologists in Nigeria is the running of STI and/ or infectious disease clinics but literature pertaining to the provision of this service is sparse. In this two-year retrospective analysis, infectious dermatoses cases constituted the bulk of out patient referrals to clinical microbiologists in the study location. The results also show the range of infectious dermatoses with which clinical microbiologists need to be adept within a single tertiary hospital.

The actual number of infectious dermatoses cases was low considering the fact that skin infections are the second most common group of dermatoses seen in Nigerian dermatology practice (10). This connotes a reliance on clinical acumen over laboratory diagnosis. The extent to which this is justified varies for individual conditions. For example, the lack of clinical microbiology consultation in the diagnosis of classical scabies is probably justified because the paucity of adult mites on an individual, usually ten to fifteen, makes sampling and microscopic identification insensitive (11). Tinea caused by dermatophytes, on the other hand, are relatively easier to diagnose in the laboratory. Otrofanowei et al noted that $80.8 \%$ of diagnoses of dermatophytosis in a tertiary hospital were made on clinical grounds without laboratory confirmation (12). This scenario is not unique to low resource settings; according to the European Onychomycosis Observatory, most general physicians and about $60.0 \%$ of dermatologists do not sample cases of suspected dermatophytosis (13).

This study revealed microbiological confirmation of the referral diagnoses in approximately three out of ten cases. This is slightly higher than the $28.0 \%$ of true positive microbiology test results for skin specimens reported by Xia et al in a United States based study (14). However it should be noted that this figure was based on bacterial and fungal cultures since parasitic diseases were not considered. While it is tempting to equate the frequency of microbiological confirmation with the accuracy of clinical judgment, one must consider variations in sensitivity of the different tests which may 
have resulted in some false negative results. For example, microscopic examination of skin snips, although highly specific, is inadequate for detecting prepatent and light Onchocerca volvulus infections (15). Sensitivity depends on a number of factors including the number of snips examined, the number of fertile female worms harboured, the distribution of microfilariae in the skin, the snip incubation medium and duration and host immune response (16). PCR and diethylcarbamazine patch test are more sensitive alternatives especially where prevalence is low (17).

Given their knowledge of quality assurance and specimen management, it is reasonable to expect that clinical microbiologists will strive to eliminate preanalytical variables which could affect test accuracy. The importance of appropriate and adequate sampling of infectious dermatoses lesions can not be overemphasized as sampling errors can account for a large number of negative tests. In dermatophytosis, for example, such errors include taking specimens from the clearing of tinea lesions instead of the edge; not targeting the junction between healthy and affected tissue in onychomycosis; not collecting adequate amount of specimen; and failing to ensure that patients have abstained from antifungal agents in the weeks prior to sampling (5).

The referrals to clinical microbiologists were predominantly mycoses and parasitic dermatoses. Bacterial skin infections other than leprosy and viral diseases like warts were conspicuously absent. Pyodermas (a terminology used to describe all superficial bacterial skin infections associated with production of pus including impetigo, ecthyma and furunculosis) are common skin infections in children both in community surveys and dermatology clinics within and outside Nigeria $(18,19)$ The absence of referrals is probably because the diagnosis of these infections is straightforward, the causative agents being usually Staphylococcus aureus and Streptococcus pyogenes which are likely to respond well to antibiotics. Since these infections are commoner in children, it may be the reason why few paediatric referrals were seen in this study. A few studies have reported methicillin resistance rate of $7.4 \%$ to $13.0 \%$ in S.aureus isolates from pyoderma in Asia $(20,21)$. Similar studies are needed in Nigeria to guide institutional antibiotic policy formulation for treatment of pyodermas.

Fungal dermatoses, especially tinea capitis/corporis were the most common referrals seen. The clinicomycologic correlation in tinea of $25.0 \%$ was lower than $48.6 \%$ to $66.0 \%$ reported from Indian studies (22-24). Thus clinical overdiagnosis of tinea may be the case in the study location. Clinicomycologic correlation for onychomycosis, at $40.0 \%$, was higher than for tinea. Efuntoye et al reported a similar rate of $41.4 \%$ in southwestern Nigeria but Gupta et al reported $59.2 \%$ in India $(25,26)$. Differentials of onychomycosis which include psoriasis, lichen planus and traumatic onchodystrophy could account for negative cases (5). Moreover, Candida and NDM were encountered among patients with microbiologically confirmed onychomycosis. These fungi may not respond to antifungals commonly prescribed for the treatment of onychomycosis, further buttressing the need for laboratory diagnosis.

With respect to the parasitic dermatoses, onchodermatitis was the commonest referral, followed by lymphatic filariasis and only one case of scabies. This distribution varies significantly from the findings in a previous dermatology clinic-based study conducted by Airuauhi et al in the same location (27). In that study, scabies was the predominant parasitic dermatosis over the five-year study period (1993 to 1998). The paucity of scabies referrals in the index study cannot be attributed to reduced prevalence of the disease because sources have reported resurgence and increasing prevalence (28). A more plausible explanation is that the diagnosis of scabies is typically clinical. Some other 
parasitic dermatoses reported by Airuahi et al such as myiasis, cutaneous larva migrans and pediculosis pubis were not encountered in this study. Interestingly, the report of Airuahi et al suggests that all diagnoses of scabies and other parasitic dermatoses were supported by laboratory evidence. Since their study was retrospective in nature, the practice of subjecting all clinically suspected cases to laboratory investigation is not likely to have been motivated by research. This implies that there has been a change in the way dermatologists utilize microbiology laboratory services in the study location. The reasons need to be identified and if necessary addressed. Referral diagnosis of skin related NTDs (onchodermatitis, lymphatic filariasis, leprosy and scabies) was common and almost as prevalent as tinea. Majority of cases of NTDs are expected to be encountered in rural communities but skin-related NTDs are reportedly also seen in urban dermatology clinics (29). Hotez et al described Nigeria as 'ground zero' for NTDs because of the high prevalence of these diseases in the country (30). Specifically, Edo state where the study site is located is highly endemic for onchocerciasis (31). In the ensuing years since the London declaration on NTDs in 2012, giant strides have been made in the control of NTDs with chemotherapy reaching a billion people in 2014 . However, the World Health Organisation (WHO) and partners have focused on mass drug administration (MDA) to the detriment of diagnostics (32).

More sensitive diagnostics are imperative in the era of successfully implemented NTD control programmes because microscopy-based tests are not sufficiently sensitive to detect residual infection. This may have accounted for the lack of microbiological confirmation in some of the cases of onchodermatitis and lymphatic filariasis seen in this location as MDA directed programmes have been implemented to control both diseases in surrounding areas (31).

An emerging concept in the control of NTDs is the integrated management of skin NTDs which is predicated on the knowledge that many of these diseases are associated with skin manifestations $(4,33)$. This trend can be leveraged to advocate for the provision of diagnostics for the skin NTDs and in extension other infectious dermatoses. Existing diagnostic tests including immunochromatographic tests like the Binax filarial antigen for lymphatic filariasis and the Dual Pathway syphilis test for yaws need to be made widely available in routine diagnostic laboratories via reliable and consistent supply chains. Nucleic acid amplification tests, increasingly available in point of care (POC) formats, should be deployed for diagnosis of skin NTDs and rolled out in a fashion akin to Gene X-pert TB. This will go a long way to improve diagnostic accuracy.

The findings of this study may not apply to other locations of practice in Nigeria. The number and variety of cases should not be interpreted as the magnitude and diversity of infectious dermatoses in the location but as those which various practitioners, mainly dermatologists, felt needed a clinical microbiologist's input. Further studies are required to assess the burden of infectious dermatoses seen in the dermatology clinic and place the demand for microbiological diagnosis in better context. The factors which determine the dermatologist's decision to consult a clinical microbiologist and the impact of such consultations on patient management need to be formally assessed.

To conclude, fungal and parasitic infectious dermatoses are commonly referred to clinical microbiologists who, therefore, need to be adept in diagnosing these conditions. Insensitive testing platforms may militate against effective diagnosis. The trending interest in integrated management of skin NTDs can be capitalized upon to advocate for more sensitive diagnostic platforms for infectious dermatoses. Further studies are needed to evaluate the demand for clinical microbiology services and their impact on the management of infectious dermatoses. 


\section{Author Contributions:}

The author was responsible for the concept, data collation and analysis, and manuscript preparation.

\section{Conflict of Interest:}

The author declares that the research was conducted in the absence of any commercial or financial relationships that could be construed as a potential conflict of interest.

\section{Acknowledgements:}

The author acknowledges the head and staff of the department of Medical Microbiology, University of Benin Teaching Hospital for their support.

\section{References:}

1. Seth, D., Cheldize, K., Brown, D., et al. Global burden of skin diseases: Inequities and Innovations. Curr Dermatol Rep. 2017; 6: 204-210.

2. Karimkhani, C., Dellavalle, R.P., Coffeng, L.E., et al. Global skin disease morbidity and mortality: an update from the Global Burden of Disease Study 2013. JAMA Dermatol. 2017; 153: 406-412.

3. Gimbel, D. C., and Legesse, T. B. Dermatopathology practice in Ethiopia. Arch Pathol Lab Med. 2013; 137: 798-804.

4. Mitjà, O., Marks, M., Bertan, L., et al. Integrated control and management of neglected tropical skin diseases. PLoS Negl Trop Dis. 2017; 11: e0005136.

5. Pihet, M., and Le Govic, Y. Reappraisal of conventional diagnosis for dermatophytes. Mycopathologia. 2017; 182: 169-180.

6. Wooster, S. L., Sandoe, J. A. T., Struthers, J. K., et al. Review of the clinical activity of medical microbiologists in a teaching hospital. J Clin Pathol. 1999; 52: 773-775.

7. Mehtar, S. Review of a consultant microbiologist's work practice- an audit. J Clin Pathol. 1995; 48: 1082-1086.

8. Balfour, A. Review of clinical activity by microbiologists. J Clin Pathol. 1996; 49: 429-431.

9. Riordan, T., Cartwright, K., Logan, M., et al. How do microbiology consultants undertake their jobs? A survey of consultant time and tasks in South West England J Clin Pathol. 2002; 55: 730-740.

10. Henshaw, E., Ibekwe, P., Adeyemi, A., et al. Dermatologic practice review of common skin diseases in Nigeria. Int Journ Health Sci Res. 2018; 8: 235-248.

11. Hengge, U. R., Currie, B. J., Jäger, G., et al. Scabies: a ubiquitous neglected skin disease. Lancet Infect Dis. 2006; 6: 769779.

12. Otrofanowei, E., Enajeroh, P., Ayanlowo, O. O., et al. Clinical diagnoses of superficial mycoses: Are clinicians over diagnosing dermatophytoses? Nigerian Association of Dermatologists. $12^{\text {th }}$ Scientific Conference and Annual General Meeting. 2018; 28-29.

13. Effendy, I., Lecha, M., Fenilhade de Chauvin, M., et al. Epidemiology and clinical classification of onychomycosis. J Eur Acad Dermatol Venerol. 2005; 15: 8-12.

14. Xia, F. D., Song, P., Joyce, C., et al. The utility of microbiological studies in diagnosis and management of suspected dermatological infection. JAMA Dermatol. 2017; 153: 1190-1192

15. Boatin, B. A., Toé, L., Alley, E. S., et al. Diagnostics in onchocerciasis: future challenges. Ann. Trop. Med. Parasitol. 1998; 92: S41-S45

16. Bottomley, C., Isham, V., Vivas-Martinez, S., et al. Modeling neglected tropical diseases diagnostics: the sensitivity of skin snips for Onchocerca volvulus in near elimination and surveillance settings. Parasit Vectors 2016; 9: 343.

17. Boatin, B. A., Toé, L., Alley, E. S., et al. Detection of Onchocerca volvulus infection in low prevalence areas: a comparison of three diagnostic methods. Parasitology 2002; 125: 545-552.

18. Emodi, I. J., Ikefuna, A. N., Uchendu, U., et al. Skin diseases among children attending the outpatient clinic of the University of Nigeria teaching Hospital, Enugu. Afri. Health Sci. 2010; 10: 362-366.

19. Mahe, A., Prual, A., Konaté, M., et al. Skin diseases of children in Mali: a public health problem. Trans R Soc Trop Med Hyg. 1995; 89: 467-470.

20. Gupta, A., Malhotra, S., Sidhu, S. K., et al. Bacteriological profile and antimicrobial susceptibility pattern of pyoderma in a tertiary care hospital. Asian Pac J Health Sci. 2017; 4: 39-42.

21. Soumya, R. R., Jayalekha, B., Sreekumary, P. K. Bacteriological profile of pyoderma in a tertiary care centre in Kerala, India. Int J Res Dermatol. 2016; 2: 1-11.

22. Hanumanthappa, H., Sarojini, K., Shilpashree, P., et al. Clinicomycological study of 150 cases of dermatophytosis in a tertiary care hospital in south India. Indian J Dermatol. 2012; 57: 322-323.

23. Bindu, V., and Pavithran, K. Clinicomycological study of dermatophytosis in Calicut. Indian J Dermatol Venereol Leprol. 2002; 68: 259-261.

24. Majeed, N., Narayanankutty, S., Rajan, R., et al. Clinicomycological study of 
dermatophytosis in a tertiary care centre. J Acad Clin Microbiol. 2016; 18: 110-113.

25. Efuntoye, M. O., Sobowale, A. A., Mabekoje, O. O., et al. Onychomycosis among rural farmers in a southwestern part of Nigeria. Egyptian Dermatol Online J. 2011; 7: 1-9.

26. Gupta, M., Sharma, N. L., Kanga, A. K., et al. Onychomycosis: clinicomycologic study of 130 patients from Himachal Pradesh, India. Indian J Dermatol Venereol Leprol. 2007; 73: 389-392.

27. Airauhi, L. U., Onunu, A. N., and Otabor, C. U. Parasitic dermatoses as seen at the University of Benin Teaching Hospital (UBTH), Benin City in Nigeria. Afr J Clin Exper Microbiol. 2003; 4: 24-30.

28. Onyekonwu, C. L., Okoh, N., Ofondu, E., et al. Incidence, pattern and trend of scabies infection in Nigeria: a retrospective study of 366 cases. Int J Med Health Dev. 2018; 23: 227-230.

29. Henshaw, E. B., Otike-Odibi, B. I., Okpa, H. O., et al. Neglected tropical skin diseases in a Nigerian tertiary hospital. Nig J Med. 2018; 27:114-122.
30. Hotez, P. J., Asojo, O. A., and Adesina, A. M. Nigeria: "Ground Zero" for the high prevalence neglected tropical diseases. PLoS Negl Trop Dis. 2012; 6: e1600.

31. Griswold, E., Eigege, A., Ityonzughul, C., et al. Evaluation of treatment coverage and enhanced mass drug administration for onchocerciasis and lymphatic filariasis in five local government areas treating twice per year in Edo State, Nigeria. Am J Trop Med Hyg. 2018; 99(2): 396-403.

32. Peeling, R. W., Boeras, D. I., and Nkengasong, J. Re-imagining the future of diagnosis of neglected tropical diseases. Comput Struct Biotechnol J. 2017; 15: 271274.

33. Engelman, D., Fuller, L. C., Solomon, A. W., et al. Opportunities for integrated control of neglected tropical diseases that affect the skin. Trends Parasitol. 2016; 32:843-854. 